\title{
Artistic Thinking of Oil Painting Element in the Film Creation-Research on Oil Painting Performance in the Animated Film
}

\author{
Hanying Jiang ${ }^{1}$, Xianfei Liang ${ }^{2}$ \\ ${ }^{1}$ Lushan College of Guangxi University of Science and Technology, Liuzhou 545000, China \\ ${ }^{2}$ Liuzhou City Vocational College, Liuzhou 545000, China
}

Keywords: Oil painting art, oil painting animation, cartoon pie

\begin{abstract}
No matter it is style, composition, color and texture element, traditional painting has a unique performance charm, and the reference of traditional painting forms and style may make animation creation rise to a higher level. If animation creation can combine traditional art essence and new science and technology, it can certainly be unique. Light and color and other elements in the oil painting can make perfect show in animation carrier to create new visual effects. At the same time, art is always intercommunication, “cartoon pie” painting reflects a revolution combining the cartoon culture and traditional painting art. Cartoon character modeling process in painting has strong recognition and fun, becoming a visual symbol, making contemporary oil painting language to diversification.
\end{abstract}

\section{Diversified development of oil painting language and evolution of animation style}

Animation is a comprehensive form of painting, digital media, film, comics, photography, music, literature and many other disciplines of the arts. With the development of time, new technology plays an important role in the animation process, and the new type of screen presentation ways has made a growing need for new technologies for animation work to be supported, but it still cannot replace the traditional painting on paper, and the form of hand-drawn animation is the most direct and simple presentation. Blind pursuit of technology usually tends to work to lose value of art appreciation. As the oldest and most traditional kind of painting, whether it is the shape, composition, color or texture elements, painting has unique performance charm, the reference of painting form and style in animation creation, combining with digital technology and film technology makes the image more realistic modeling, which plays a fresh visual experience for animation character design and scenarios construction and achieves the perfect picture effect. Painting is an important part of the visual language of animation, painting and animation are closely linked, although the animation is from the painting, it is different from traditional painting. Drawing is the basis for the animation, the animation also has its own unique painting style. The introduction of painting style into contemporary animation, with technology and art combination can increase the art height of animation, forming specific style of relatively strong identification.

Research on oil painting figurative realism language performance in the animated film. So far, animation development expression has many forms, which can be divided into two kinds including two-dimensional animation and three-dimensional animation, with the painting techniques of intervention, for example, the 1997 Artist of Russia Alexander Petrov's animated film "The Old Man” is completed using this new creative forms. Oil painting on glass, due to the feature that paint is not easy to dry, will help screen to change again, and the choice for a variety of color makes picture effect performance. Stroke of unexpected liquidity generates special effects in the continuing process of painting. The perfect combination of beautiful screen, full rhythm narrative 
and film audio-visual language, from many sea view in the animated film "The Old Man", we can see the shadow of Turner's seascape painting "snowstorm - Steamboat leaving a port" and "Sea Fisherman” and other works. In Turner works, light generally guided sight changes, sporty light and color create a highly rhythmic beauty of rhythm visually similar to artistic expression embodied in animated movie scene light of "The Old Man". Wave, mist, dynamic changes of the ship, brilliant colors, hazy mood, great scene, so as to make the screen produce a dynamic tension, reflecting the tense and dramatic of scene. The animated painting approach in "The Old Man" is full of life, passion, passion bearer wild strokes makes the screen realistic and narrative, and unique sense of texture strokes in painting constitutes the performance factor of works conveying emotion. According to Tuo Dostoevsky's “Crime and Punishment” animated “Dream Ridiculous Man”, it is about a man with despair life and ready to commit suicide, who makes new life for unexpected encountering a little girl. The overall is full of philosophical meaning, painting style better able to express philosophizing about life, and reflects the serious topic of life. In "Spring Awakening” and “The Little Mermaid”, Petrov also use the color, texture and shape in painting for artistic expression creation, every frame is a separate painting, with film and painting together to create a unique visual effects. In painting animation film and television creation, the painting integrated into the animation is no longer an objective depiction of stationary object. Paint itself has vitality, and it can be created and performed. If in the animated painting “The Old Man”, "Spring Awakening” and "The Little Mermaid”, Petrov assimilated composition, brushwork, texture and color into the painting animation, then the animated film "Angels” is set in characters contemporary oil which is absorbed in the character modeling realistic figurative painting form. The film draws the thick rich ethnic style in painters Ai Xuan's “Breeze Swept Hair” and Chen Danqing’s masterpiece “Tibet Paintings”, with the perfect combination of animation technology and oil painting effects, simulating painting brush strokes texture and pursuing real texture effects, which is novel and unique. Black, gray and violet color painting made the movie screen have a heavy sense of the vicissitudes of life, with the screen real delicate and scene grand, with artistic strong infection. The combination of realistic painting style and animation technology expanded the new styles of animated movie.

Surrealist painting style and animation film-making. Freud's "The Interpretation of Dreams" opened a new era of psychoanalysis. Surrealism originated from Dada, which attempted to combine the dream and reality, with mysterious, grotesque features in the picture. The representative concludes Daly’s “Eternal Memory”, etc., surrealistic paintings proposed to give up a logical, orderly life image of reality, through the unconscious fantasies, irrational absurdity reconstruction of each element in dreams, exaggerated weird, anachronistic, to create a fantasy world unlike real attempt. Metaphor and symbol are commonly used means in surrealistic paintings, and the surreal animation style often travels between the real and the surreal, reality and absurdity, cruelty and humor. Effect of surrealistic paintings on animation is very far-reaching, because of its creation and production characteristics, animation art has its unique doomed surreal feeling. The use and development of surrealist painting style in animation makes animation on the aesthetic consciousness have two characteristics: The first is artistic reproduction of objective things, the second is self-expression of subjective spirit. Using surrealist ideas makes the animation from the vulgar to rise to the expression of a broad spectrum of ideas and concepts on the level of artistic creation. The representative includes "the giant bird feathers and travel", super giant feather with reality-style in animated film went through the Paris landmark in the wind, panorama to show the charming sceneries of Paris, giant feather like the huge aircraft ships crossed over the city, giant modeling of birds with exaggerated proportion, fantasy, gives a new visual experience, surrealist painting style application makes the animation film industry unique. With the digital virtual 
technology continuing to improve expressive, the expression of surreal mood makes animation reach a new height.

\section{Rousseau painting "immature beauty" and the three-dimensional animation scene} production. French painter Henri Rousseau never received any professional training in painting in his life, and his work ignored the principle of perspective in Western painting tradition pursued, abandoned academic painting of usual way, with a positive habit of paint approach to express the innocence, rustic, full of childlike innocence and fairy-tale fantasy, and the details of just right process forms a perfect composition, poetic expression of the mysterious presence. Light and shade and perspective space is after plane decoration. In Rousseau's picture, it is not easy for us to see a life scene and deep-seated sense of perspective. Rousseau art reflects the unconventional nature, and colorful color solidification above the screen reflects the quiet atmosphere, naturalism original flavor full of decorative means mavericks in academic style. Rousseau's "immature beauty" style has been extended to the creation of animated films in the role setting in "one thousand and two nights”, clothing accessories and three-dimensional scene animation production using Rousseau full of original taste decor is refreshing, and the combination of 2D and 3D scene design constructed typical mosaic building in the Middle East, which is unique. Jungles, flowers and trees were simply depicted with children's common inherent color in drawings, with the image of each picture remaining absolutely clear sense, and the overall tendency was cool tone, plain color painting with decorative means let the whole picture become quiet, so that the entire film is full of magical fantasy and romanticism, and Rousseau-style "Immature Beauty" is on its head. The same painting style was also successfully used in the animated film "Madagascar", Two-thirds of whose scenes were happening in the jungle, thick and lush tropical plants nuances portrayed lifelike and the jungle design inspiration source was from the French painter Henri Rousseau's paintings, with videos showing the overall retro style. Rousseau's painting style is full of strong and distinctive personality, he described a world full of mysterious and playful. If animation creation is able to combine traditional art extract and new science and technology, it can certainly be unique. As we all know, with the three-dimensional software increasingly simplistic and intelligent, digital technology will become a new way of public recreation, the traditional art of the West representative will be easily overlooked and forgotten, doodles animation scenes and processing random collage grafted wanton spread in the network, it is inevitable to form the innovative spirit loss of creation and stylized production model, resulting in shoddy film. Therefore, the three-dimensional animation scene production demands designer with higher aesthetic cultivation, and the reference of traditional painting form will make animation creation rise to a higher level.

Reference of animated films for Post-Impressionist style. "Loving Vincent" is an animated short film with tribute to the genius, based on the Van Gogh's 120 original and 800 personal letters, reproducing the 20 virtual characters in the form of 56800 oil paintings, by Van Gogh narrative in figure painting to tell the story of Van Gogh's lonely life with full of anxiety. The animation film continued Van Gogh's postimpressionist style as a whole, and color is no longer a real portray reality, no longer serves the light and space but more emphasis on the spirit of self-expression. Flowing strokes texture, decorative color, reflecting a pure immature beauty, whether it is a "Wheat Field with Crows on" or "Night Coffee Shop" or those self-portraits of different periods, strokes all expressed deepest loneliness, despair and struggle against fate. Each frame of the movie consists of highly reduced Van Gogh painting during his lifetime by a number of painters with the presentation way of digital synthesis to post-production, finally grinding out such a masterpiece of animation industry, becoming the first Van Gogh style animated film to complete a single frame painting production with editing style and allow people to enjoy the charm of postimpressionist masterpieces 
while watching stop-motion animation.

\section{Schemata reproduction of animation culture - “Cartoon Pie” oil painting}

Early "Cartoon Pie" refers to a group of artists that grew up in the sixties and seventies in China, and the works were mostly drawings reproduced with the animation culture acceptance and criticism. The new "Cartoon Pie" refers to a group of artists that grew up in the late 1980s, and their growth environment, habits, ways of thinking and creative way are marked with the stigma of animation culture, the whisper head dyed of growing environment made their works full of animation culture digestion, and the style was kitsch or cartoon, with a reflection of the life times and growing confusion. "Cartoon Pie" painting reflects a revolution combining the traditional animation and painting art, the picture cartoon process in character modeling has strong recognition and fun and has become a visual symbol, and the representing cutting-edge painters include Chen Ke, Xiong Yu et al., who are called the "new cartoon generation". The work is not simply copying the animation image, character modeling is not rough planarization treatment on the cartoon image or becomes simple visual symbols, but rather a re-creation of art, which becomes joyful, painful, decadent, progressive youth Story of 80s generations. The new cartoon painting is different from scar art and the local painting, for example, the characters Xiong's painting has a solemn beauty of mechanical metal, elongate neck, blue eyes, which gives a sense of distance, and the cold gray tone processing is often used in 3D animation scene. Chen's paintings show a strong scenario and narrative with the girl image in picture melancholy and self-enclosed, and the cartoon treatment seems to take us back distant childhood. The authors of "Cartoon Pie" seem to create another spiritual realm of the "I", in which character modeling is exaggerated, color is more subjective. The cartoon image is the feature of the "Cartoon Pie" painting, weakening traditional painting, erasing much the character background and extraneous details, with color processing simple and direct, and the reference of animation modeling makes easel painting begin to make new thinking.

Thus, the exchange between art is always fusion, with innovative new technologies and animation style after another, whether it is Chinese or Western-style ink painting animation, it will bring the animated film industry new challenges and exploration. The light and color and other painting elements can make perfect show in vector animation, creating a new visual effects that makes the art style of animated film get a new promotion and breakthrough. The animation modeling reference of "Cartoon Pie" painting is a new attempt, and the oil painting language begins to diversify.

\section{References}

[1] Chen G. Animation art style settings - animation videos. Communication University of China press, 2012. (In Chinese)

[2] Zhang R. Research on the visual characteristics of cartoon painting. Popular Literature(Theory Edition), 2009. (In Chinese)

[3] Chen X. New thinking of animation scene design under the guidance of surrealism art concept. Zhuangshi, 2013. (In Chinese) 